\title{
Correlation between the roughness of the substrate surface and the debonding risk
}

\author{
F.Perez, M. Morency, B.Bissonnette \\ Laval University, Québec, Canada
}

Civil Engineering Department

Email: Fabien.Perez@gci.ulaval.ca

L. Courard

University of Liège, Belgium

GEOMAC Department, University of Liège

\begin{abstract}
This paper presents the influence of substrate surface preparation on the adhesion strength of repaired beams system. Bond between new and old concrete has been the subject of a number of investigations, but in most cases, only adhesion strength was addressed. This parameter was used to estimate the durability and/or the debonding risk for repaired structure and it's a generally accepted auditing standards. Usually, surface preparation of the substrate concrete is considered essential to achieve a durable repair because of its influence on the bond strength. To better understand debonding mechanism, in particular these related to surface preparation, roughness parameters were calculated to quantify the influence of surface preparation on the structural behaviour. Using this approach, repair beams prepared by way of four (4) concrete surface preparations were characterized. Results obtained show that repaired beams presenting a substrate with a rough surface permit to achieve a monolithic behaviour of the repaired system. Opposite structural behaviour, with large debonding, was recorded for those having smooth surface. However, all surface preparations used have promoted the same bond strength regardless the roughness of the substrate. The resulting analysis highlights the relation between roughness parameter $\alpha_{\text {rough }}$ and the debonding mechanism of repaired beams. Such results will be useful to better predict the performance of concrete repairs.
\end{abstract}

\section{INTRODUCTION}

Many existing concrete structures are deteriorated and need to be replaced or rehabilitated. Deteriorations are often localized at the surface due to exposition to severe weathering conditions (de-icing salts and freeze-thaw cycles). Thin bonded concrete repair overlays are among promising rehabilitation approaches to extend the service life of bridge desks. A number of debonding mechanisms have been developed based on field observations and on mechanical considerations [Saiidi et al 90, Granju 96]. A literature survey showed that debonding occurs only when a crack reaches the interface [Ong et al 95, Bernard 00, Granju 01]. In this case, the crack induces a specific state of disturbance at the interface. It means that the generated stress $\sigma_{y}$, perpendicular to the interface, could exceed the tensile strength of the overlay material (new concrete layer) if tensile stress is above the tensile strength obond. Consequently, debonding is initiated in tension perpendicular to the interface [Hilsdorf et al 92, Bijen et al 94]. Therefore, the tensile strength is con- sidered as a critical design parameter and the tensile stress perpendicular to the interface controls the debonding mechanism. Initiated by tension stress, debonding propagation in mode I is due to a combination of tension and shear stresses [Hilsdorf et al 92, Bijen et al 94, Granju 04]. There are two approaches to minimize the debonding risk. The first one is to minimize the magnitude of $\sigma_{\mathrm{y}}$ and it will not described in this article. The second one is to develop a good adhesion. However, it is complex to define what a good interface is. There is no unique bond strength value above which debonding is not possible. Literature survey indicates that a bond strength ranging from 1,50 MPa [Concrete Society 91, Granju 96] to $2,80 \mathrm{MPa}$ [Silfwerbrand 90, Bernard 00] is recommended and seems to be sufficient to have a monolithic behavior. Nevertheless, others results indicates that relation the influence of the bond strength on debonding is systematic. It should be noted that in-situ tensile strength ranging between 1,30 and 2,09 $\mathrm{MPa}$ were measured on concrete beams without presenting any sign of debonding [Laurence 01]. But some results 
found in literature are in contradiction with this approach, especially regarding the influence of the tensile strength of the interface. Debonding has been observed in the field even if bond strength was above the limit of 1,5 MPa [Mellinger 63, Wheat 93, Lupien 95, Scapinato 96]. Event if, the relation roughness/bond strength isn't yet established, the surface preparation has an impact on the behaviour of repaired structures. If the surface treatment induces a too flat roughness, debonding has been seen on overlay [Cusson et al 96, Wheat et al 93, Ong et al 95].

The adhesion, and consequently the durability of a repair, depends on various phenomenons taking place in the interfacial zone [Courard 99]: the wettability of concrete substrate by the repair materials, concrete surface geometry, rheology of the repair concrete, roughness of the substrate surface, etc... The last one is often presented as the most important factor to achieve a good bond. This improvement is mainly assigned to the increase of the contact surface [Talbot et al 94, Santos et al 07]. But other results suggested that roughness has no relevant effect on the bond strength [Silfwerbrand 90, Courard 99, Perez 05, Belair 06]. This misleading on the influence of roughness come from that roughness is often approached or evaluated with non effective method which give qualitative or not precise enough information.

Roughness is usually assessed only qualitatively; by visually observing the substrate surface and by classifying it from very smooth to very rough with rubber reference surfaces [ICRI Surface Preparation Guide 03732] Theses panels provide a simple tool for specifying and evaluating surface preparation, but, it still remains rather subjective. Nevertheless, these methods are unable to provide a sufficiently detailed representation of the actual surface profile for the calculation of morphological and statistical parameters. In order to achieve a reliable quantitative analysis of superficial concrete morphology after surface preparation, methods applied in other engineering sciences have been used in concrete field [Chiai et al 98, Courard 00, Maerz et al 01, Perez et al 03, Garbacz et al 05, Santos et al 07]. The authors [Courard 99, Perez 05] recently implemented a system of this type based on Moire interferometry and observation of the shadows produced by the roughness of the concrete substrate [Perez 05, Perez 07]. In all cases, the aim of these kinds of research was to adopt roughness parameters and correlate these with bond strength for design codes [Chiai et al 98, Courard 00, Maerz et al 01, Perez 05, Santos et al 07]. These methods would help to estimate the real influence of roughness on bond strength and evaluate the durability of the repair system.

\section{EXPERIMENTAL WORK}

The aim of the research is to better understand the mechanisms involved in the cracking behavior of bonded overlays used on reinforced concrete beams and slabs. The project involves the testing of real size reinforced concrete beams repaired with concrete overlays using four different types of surface preparation and subjected to static flexural loading. The concrete beam specimens were simply supported with a point load at midspan. Structural capacity (evolution of the apparent rigidity, maximum deflection, failure mode) and cracking behavior (flexural cracking and interface debonding) were monitored.

\subsection{General procedure}

In this study, a systematic procedure was used to quantify surface roughness. The collected data were connected to the tensile bond strength and to the structural behavior of the repaired concrete beams. More details on the operating procedure are available in Perez [Perez 07]. The substrates were cast following the method described below this part. When surface preparation completed, an optical profilometer was used to quantify the surface roughness and then, the beams were repaired with similar concrete mixture. The beams were subjected to static loading test. Deflection and crack propagation were measured and record to evaluate the structural behavior. After loading test, numerous cores and samples taken from the repaired concrete beams were used to perform three types of (3) bond strength tests. Verifications made showed that in these collecting sections, the bond was not influenced by the mechanical loading. Then, an optical profilometer was used to quantify the surface roughness of the substrate interface break surface after the direct tension test.

\subsection{Description of materials}

A total of 25 beams was manufactured; five specimens for each of the four surface preparation techniques and five control specimens (not repaired). All the beams specimens were rectangular in crosssection $200 \times 210 \mathrm{~mm}$, and of length $1750 \mathrm{~mm}$. The concrete mix design is given in table 1 .

The specimens were made with ordinary Portland cement concrete (type I cement, 0,45 water to ce- 
ment ratio, $6 \%$ air content and nominal $45 \mathrm{MPa}$ compressive strength, $5-20 \mathrm{~mm}$ coarse aggregate). The repairs were made with a micro-concrete (aggregate diameter less than $10 \mathrm{~mm}$ ) with a lower water-cement ratio than the concrete used to cast the beams. Selection of repair mixture was based on recommendation from the Québec DOT and also because it is used as a reference material in many ongoing research projects conducted at Université Laval in relation with repair and rehabilitation (type I cement, 0,40 water to cement ratio, $6 \%$ air content and nominal $55 \mathrm{MPa}$ compressive strength, 5-10 mm coarse aggregate).

Table 1 : Mixtures proportions for base and repair materials

\begin{tabular}{|l|r|r|r|}
\hline \multicolumn{2}{|c|}{ Mixture $\left(/ \mathrm{m}^{3}\right)$} & Substrate & Repair \\
\hline \multicolumn{2}{|c|}{ W/C } & 0,45 & 0,40 \\
\hline Cement type 10 & $(\mathrm{kg})$ & 425 & 400 \\
\hline Water & $(\mathrm{kg})$ & 164 & 160 \\
\hline Sand & $(\mathrm{kg})$ & 715 & 854 \\
\hline $\begin{array}{l}\text { Granite coarse } \\
\text { aggregate (5-10) }\end{array}$ & $(\mathrm{kg})$ & & 861 \\
\hline $\begin{array}{l}\text { Granite coarse } \\
\text { aggregate (5-20) }\end{array}$ & $(\mathrm{kg})$ & 1025 & \\
\hline Admixtures & & & \\
\hline WR 75 & $(\mathrm{ml})$ & 250 & \\
\hline SPN & $(\mathrm{ml})$ & & 2750 \\
\hline Air entrainer & $(\mathrm{ml})$ & 35 & \\
\hline Slump test & $(\mathrm{mm})$ & $70-120$ & $50-100$ \\
\hline Air entrained & $(\%)$ & $6-7$ & $6-8$ \\
\hline
\end{tabular}

\subsubsection{Surface Treatments}

All preparations were done on a non-formworked surface. A detailed visual inspection of all prepared surfaces revealed the following macroscopic and visible effects for the different surface preparation methods:

- Scarification (SCA): It generally induces grooves in one direction (preferentially oriented macro-roughness), which the operator eliminated in this study by means of successive transverse and perpendicular passes.

- Sandblasting (SAB): It was done using grade 5 sand $(1-1,4 \mathrm{~mm})$ projected according to the TS-29. Sandblasting removes the surface laitance without inducing a high roughness. The sandblasting slightly exposed the aggregates (less than half of the diameter of the maximum size aggregate).

- Chipping hammer followed by sandblasting (PJ7S): In this study, low weight jackhammer $(7 \mathrm{~kg})$ was used to minimize side-effects on substrate integrity. In addition, it should be stated that all surfaces prepared with a chipping hammer were followed by thorough sandblasting, a quite effective mean to re- move dust and loose particles. The surface profile is characterized by large waves with high amplitudes.

- High-pressure water jetting (WJ): This surface preparation technique uses a high pressure water jet (in this case: $125 \mathrm{MPa}$ pressure and $27 \mathrm{~L} / \mathrm{h}$ water flow). It induces a particular texture characterized by large waves, mostly parallel to the water flow.

\subsection{Roughness parameters}

In Table 2, a summary of basic surface parameters is provided and more information about theses parameters is available in previous work [Perez 07, Courard 00]. These parameters are determined using the mean line as a reference. The mean line is determined for any point of the actual profile by calculating the Gaussian mean value derived from adjacent points. These parameters appear to be the most useful for concrete surface characterization [Courard 00, Abu-Tair et al 00, Perez 05].

\section{Table 2 : Profile statistical parameters}

\begin{tabular}{|c|c|c|}
\hline $\begin{array}{l}\mathrm{Pa}- \\
\text { ram- } \\
\text { eter }\end{array}$ & Definition & References \\
\hline $\mathrm{R}_{\mathrm{a}}$ & $\begin{array}{l}\text { Arithmetical mean deviation of } \\
\text { the profile }(\mathrm{mm})\end{array}$ & $\begin{array}{l}\text { DIN 4768/1, ANSI/ } \\
\text { ASME } \\
46.1-1985\end{array}$ \\
\hline $\mathrm{S}_{\mathrm{m}}$ & $\begin{array}{l}\text { Mean spacing between profile } \\
\text { peaks at the mean line, mea- } \\
\text { sured over the assessment } \\
\text { length }(\mathrm{mm})\end{array}$ & $\begin{array}{lr}\text { ISO } & 4768, \\
\text { ANSI/ASME } & \text { B } \\
46.1-1985\end{array}$ \\
\hline $\mathrm{I}_{\mathrm{ss}}$ & $\begin{array}{l}\text { Increasing of the specific sur- } \\
\text { face. Ratio of projected surface } \\
\text { under real surface }(\%)\end{array}$ & \\
\hline $\mathrm{C}_{\mathrm{F}}$ & $\begin{array}{l}\text { Depth of the profile, excluding } \\
\text { high peaks and holes }(\mathrm{mm})\end{array}$ & $\begin{array}{l}\text { ANSI/ASME } \\
46.1-1985\end{array}$ \\
\hline$\alpha_{\text {rough }}$ & $\begin{array}{l}\text { Mean angle of the profile (de- } \\
\text { gree) }\end{array}$ & $\begin{array}{l}\text { ANSI/ASME } \quad \text { B } \\
46.1-1985\end{array}$ \\
\hline
\end{tabular}

All parameters are calculated in $x$ and $y$ direction. The values presented in this article were the meaning of both direction analyses. Generally, surface preparations induced no isotropic roughness.

For instance, the arithmetical mean deviation of the profile $\left(\mathbf{R}_{\mathbf{a}}\right)$ is used in the monitoring of production processes where gradual changes in surface finish due to cutting wear can occur. It is in fact the most common parameter referred in the literature to describe roughness [Silfwerbrand 90, Courard 99, Maerz et al 01, Perez 05]. Another useful surface analysis tool is the Abbott's bearing ratio curve [Courard 99] a 1-D representation of the mean surface profile. The surface parameters calculated from that curve provide information not only on local roughness, but also on the whole surface profile. $\mathbf{C}_{\mathbf{F}}$ 
(bearing coefficient): the depth of the profile excluding high peaks and deep valleys; it is evaluated from the vertical height of the Abbott's curve approximately linear segment, assumed here to extend from $20 \%$ to $70 \%$ in terms of bearing ratio values. The $\mathrm{C}_{\mathrm{F}}$ parameter gives an indication of the surface flatness: the lower is the $\mathrm{C}_{\mathrm{F}}$ value, the flatter is the profile. Finally, the parameter $\alpha_{\text {rough }}$ is calculate by the combination of $\mathrm{C}_{\mathrm{F}}$ and $\mathrm{S}_{\mathrm{m}}$ as equation below shows:

$\alpha_{\text {rough }}=\tan ^{-1}\left(\frac{4 \times C_{F}}{S_{m}}\right)$

The parameter $\alpha_{\text {rough }}$ represents the angle between the horizontal level and the mean profile of the surface. $\alpha_{\text {rough }}$ is included between 0 and 90 degree.

\subsection{Bond strength characterization}

It exist many techniques to characterize the bond strength of a repair system. In this work, two (2) were used. A short description of each test is available in the figure 1 .

Usually, the quality of a repair system is evaluated through a direct tension test. In field condition, a pull-off tester can be used to perform tensile bond test. This paper presents a more suitable direct tensile (DT) test that was used because of its lower variability (figure 1-a)). Correlation between pull-off test and direct tensile test has been done and is presented in Perez [Perez 05]. In all cases, results indicate that mean value is similar with both tests. The bond strength in tension was done for the composite made from the four 4 surface preparation.

To measure the direct shear bond (DS), the same type of core is placed in a 'guillotine' apparatus (figure 1-b). Due to limitation of the amplitude in the shear plan, only smooth interface can be tested with this setup. Based on this restriction, only shear strength for SAB and SCA has been evaluated. All tests were performed at least 7 month after casting of the substrates.
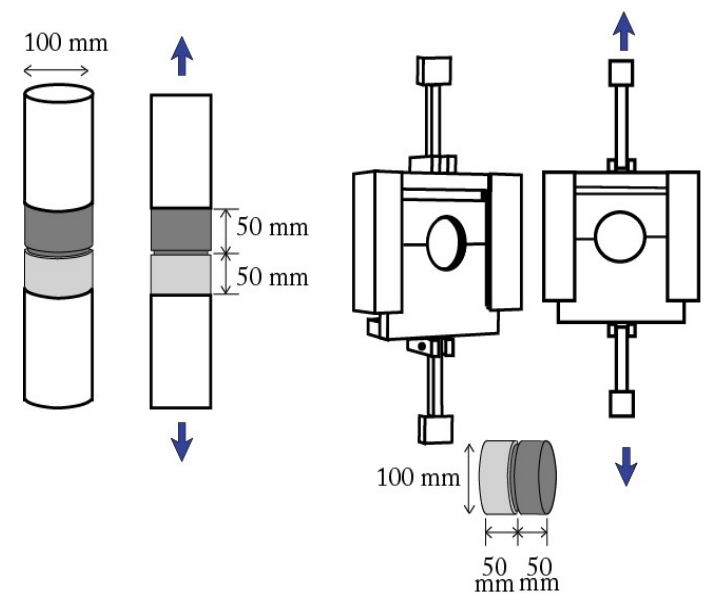

a)

b)

Figure 1: Description of the bonding test: a) the direct tension test and $b$ ) the direct shear test

\subsection{Debonding observations}

The debonding observations were presented in previous works [Perez 07]. A summary description of the procedure used to characterize and map the pattern of cracks is made below. Three (3) successive methods were used.

The initiation of all cracks was detected with the eye. After each crack occurrence, or after each cycle, the initiation and propagation of all cracks were marked carefully at the concrete surface, and the widths of few cracks were measured using a crack microscope with a resolution of $20 \mu \mathrm{m}$.

Then, LVDT is placed to measure the displacement of two points located on either side of the crack. Resolution of this LVDT is about $5 \mu \mathrm{m} / \mathrm{m}$ and the extension is $\pm 800 \mu \mathrm{m}$. These captors were used to follow the width of a debonding crack or a vertical crack.

Cracks mapping consists of a picture of the transparency film shot with a digital camera and the colors removed with imaging software.

\section{RESULTS}

\subsection{Surface topography characterization}

\subsubsection{Before repaired operation}

In accordance with the procedure described, four (4) optical profilometry measurements were performed before placing the repair material. The results of two (2) profiles are presented in figure 2.

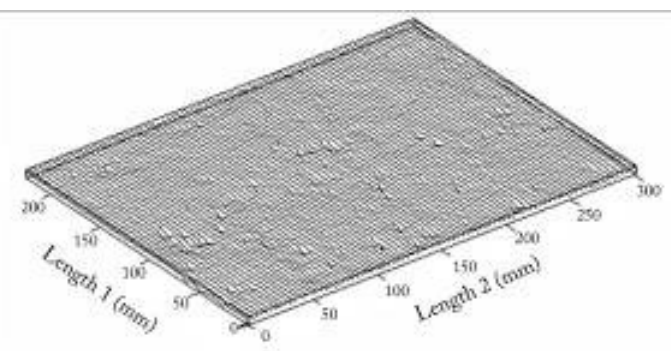

a) Scarification (SCA)

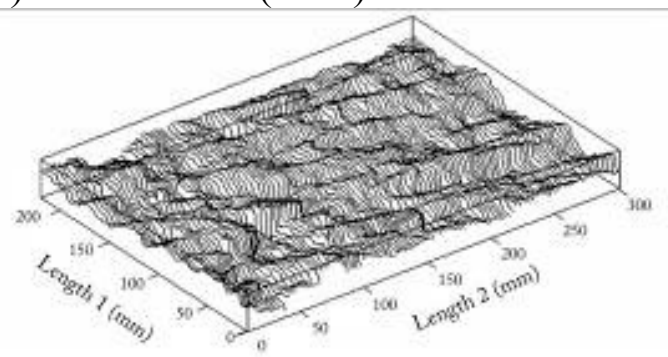

b) Water jetting $(\mathrm{WJ})$ 
Figure 2 : Profiles obtained with different types for SCA and WJ surface preparation.

From the roughness parameters summarized in table 3 , it can be seen that the $\mathrm{R}_{\mathrm{a}}$ value is approximately ten (10) times greater for both HYD and JP7S than values obtained with SCA and SAB, which produced a rather smooth surface. Abbott's parameter $\left(\mathrm{C}_{\mathrm{F}}\right)$ gives consistent representations of the influence of surface treatment on roughness. As shown in table 3, SCA surface is two (2) time flatter than SAB. All parameters pointed out the fact that HYD and JP7S induce two (2) very similar roughness. SCA gave the smoother surface with a profile comparable to a formworked surface. SAB induced a typical surface in which roughness is produced by the aggregate. Water jetting (HYD) and Pneumatic jackhammer (PJ7S) induced a much rougher profile than scarification (SCA) and sandblasting (SAB). All parameters indicated clearly that roughness is higher when energy invested in the surface preparation was.

Table 3 : Roughness parameters for the 4 surfaces preparation

\begin{tabular}{|l|l|l|l|l|l|}
\hline $\begin{array}{l}\text { Roughness } \\
\text { Parameters }\end{array}$ & SCA & SAB & PJ7S & WJ \\
\hline Under substrate & & & & \\
\hline $\mathrm{R}_{\mathrm{a}}$ & $(\mathrm{mm})$ & 0,24 & 0,46 & 2,64 & 2,25 \\
\hline $\mathrm{S}_{\mathrm{m}}$ & $(\mathrm{mm})$ & 9,40 & 9,50 & 44,00 & 31,00 \\
\hline$\alpha_{\text {roughness }}$ & $($ degree$)$ & 5,9 & 10,9 & 13,4 & 16,2 \\
\hline $\mathrm{I}_{\mathrm{ss}}$ & $(\%)$ & 1,023 & 1,093 & 1,126 & 1,287 \\
\hline $\mathrm{C}_{\mathrm{F}}$ & $(\mathrm{mm})$ & 0,41 & 0,87 & 4,71 & 4,30 \\
\hline After tensile test & & & & \\
\hline$\alpha_{\text {roughness }}$ & (degree) & 4,3 & 8,5 & 11,8 & 12,5 \\
\hline
\end{tabular}

\subsubsection{After repaired operation}

Optical profilometry measurements were performed under the substrate section after the tensile test. The maps of ruptured surface were made under sample tested in tension as show in the figure 3-a). The surface digitalized was about $75 \times 75 \mathrm{~mm}$. A detailed visual inspection of all specimens' surfaces revealed the following macroscopic and visible effects for the different surface preparation methods: There were more aggregates ruptured for $\mathrm{WJ}$ and MP7S than for SAB. No aggregates ruptured for SCA were observed (big aggregates are black in the picture on the figure 3-a). As depicted in the figure 3-b), flatter was the surface preparation and flatter is the breaks surface. There was more repaired mortar at the breaks surface for initial flat surface than for rough surface figure 3-b).
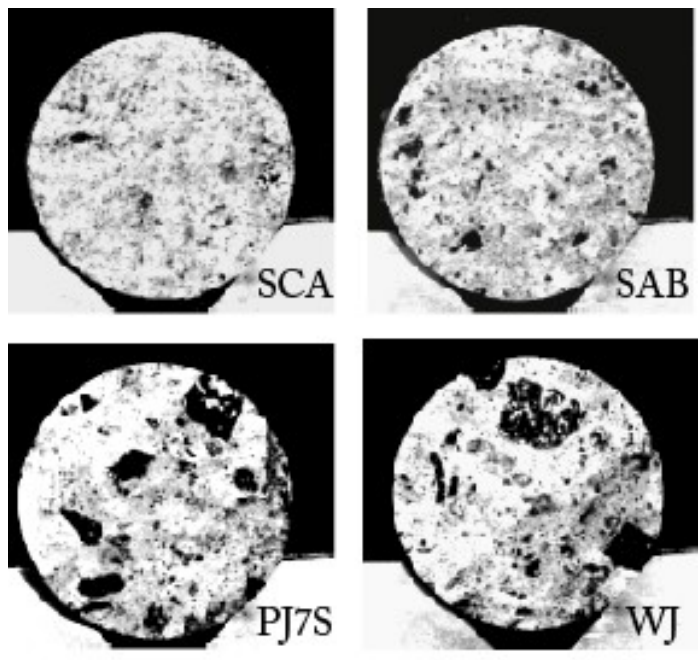

a)

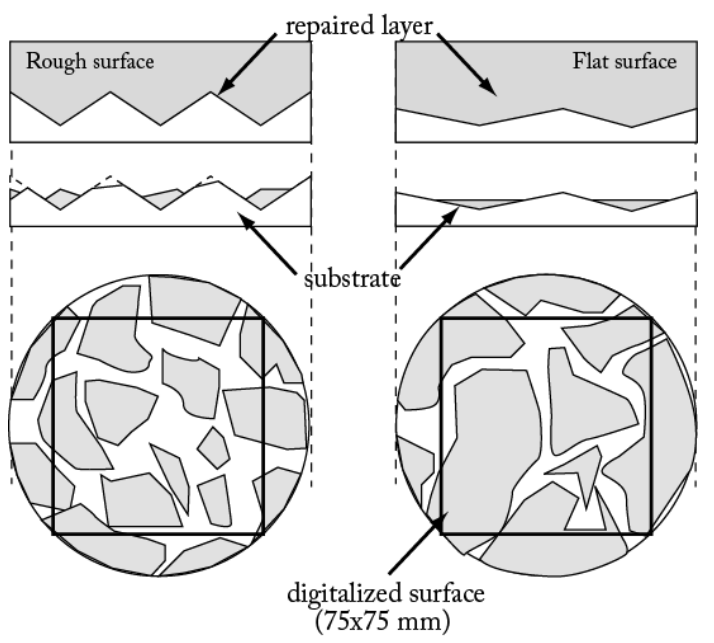

b)

Figure 3 : Surface ruptured after tensile test.

\subsubsection{Analysis}

The objective of these two periods of measure was to evaluate the cracks pattern after rupture in comparison to the initial roughness of the substrate surface. Since the interface is the weakness link, the rupture should take place along this plan. The observation of the failure mode was instructive to the comprehension of the adhesion mechanism. As results showed, the breaks surface did not corresponded systematically with the initial substrate surface. When the roughness went up a certain level, the break surface was not influence by the initial roughness. The analysis of the surfaces with two roughness parameter, $\alpha_{\text {rough }}$, illustrated in figure 4 , this effect. When substrate roughness is higher than $\alpha_{\text {rough }}$ $=10$ degree, the pattern of cracking is similar regardless the initial roughness. In this condition, the propagation of the cracks did not follow the interface zone and monolithic rupture occurred. 


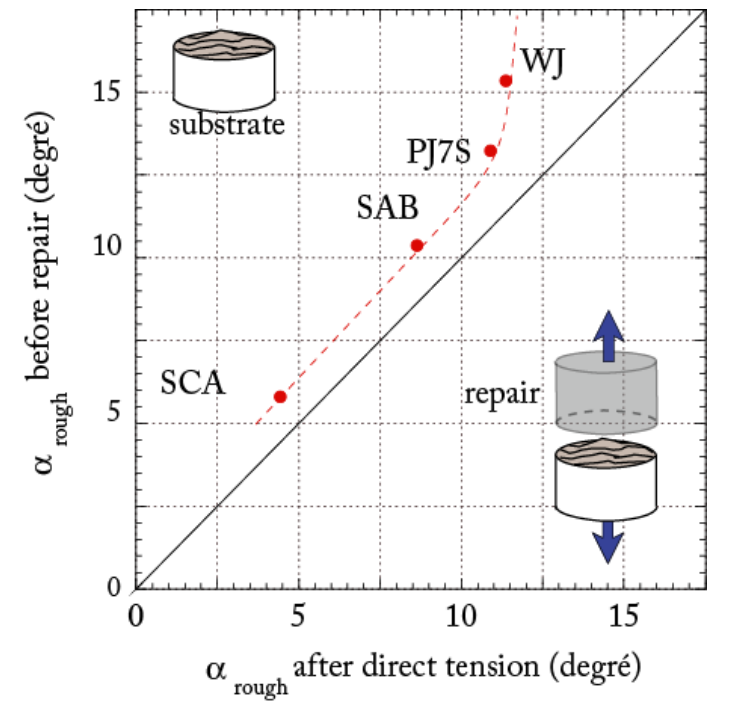

Figure 4: Comparison of the surface of the substrate and the break surface after a direct tensile test by means of the parameters $\alpha_{\text {rough }}$.

\subsection{Adhesion Evaluation}

Thirty-four (34) cores and five (5) rectangular wedge splitting specimens were used to characterize the influence of the surface preparation on the bond strength. Table 4 presents the results of the mechanical properties of the interface for both tensile and shear test as a function of the surface preparation. As shown in previous studies [Silfwerbrand 86, Talbot et al 94, Courard 05], bond strength depend on the method used to promote roughness of the substrate surface. Previous works has show that the jack-hammer preparation technique is potentially harmful for the concrete substrate superficial layer [Talbot et al 94, Belair 06]. Some significant cracking is induced, and it is likely to reduce bond/adhesion between the repair material and the old concrete as shows in table 4

\section{Adhesion strength}

For all surfaces, bond strengths were very good compared to those typically obtained in field and the results are above the recommended threshold value of 1,5 MPa. As table 4 indicates, excepted for PJ7S, for which there are little difference between the bond obtained with the three (3) others methods (SCA, SAB and HYD). The results were therefore analyzed using a statistical test based on StudentFishers' law. It shows that the type of surface preparation does not have a significant influence on adhesion strength. As explained before, the jack-hammered surface provided the lowest bond strength [Courard et al 05].

\section{Shear strength}

The direct shear test results were analyzed with the same statistical approach. Results shown that the surface preparation does not have a significant influence on the shear bond strength. The shear strengths are 2 times bigger than adhesion strengths. As noted, the tensile strength of the bond is generally considered to be half of its shear strength [Sancier 90, Granju 96, Chausson et al 98, Momayez et al 05]. In this case, the ratio is about 0,42 for SCA surfaces and 0,45 for SAB surface.

Table 4 : Mechanical properties of the interface

\begin{tabular}{|l|l|l|l|l|}
\cline { 2 - 5 } \multicolumn{1}{c|}{} & \multicolumn{2}{c|}{ DT } & \multicolumn{2}{c|}{ DS } \\
\hline Surface treatment & $\begin{array}{l}\text { Mean } \\
\text { value } \\
(\mathrm{MPa})\end{array}$ & $\mathrm{Nb}$ & $\begin{array}{l}\text { Mean } \\
\text { value } \\
(\mathrm{MPa})\end{array}$ & $\mathrm{Nb}$ \\
\hline SCA & 2,60 & 5 & 5,77 & 5 \\
\hline SAB & 2,42 & 9 & 5,87 & 5 \\
\hline PJ7S & 1,81 & 6 & - & - \\
\hline WJ & 2,71 & 4 & - & - \\
\hline Substrate & $3,26^{*}$ & & & \\
\hline Repair & $3.20^{*}$ & & & \\
\hline
\end{tabular}

\section{ANALYSIS}

\subsection{Relation bond strength and roughness}

The relation between surface roughness and bond strength is plotted in figure 5. Many roughness parameters were used to test this relation, but only one was plot. It's the comparison of tensile strength and $\mathrm{R}_{\mathrm{a}}$. As stated, this parameter $\mathrm{R}_{\mathrm{a}}$ is the most commonly used in literature. But, comparable conclusions could be made using others parameters [Perez et al 08].

In first approximation, it seems that there is no relationship between roughness and adhesion. The results confirmed those obtained by Belair [Belair 2006]. Previous studies [Courard 99, Garbacz et al 05] have showed that at microscopic level roughness induced by the different surface preparations are very similar. An in-depth analysis of the microscopic roughness was made for the four (4) surface preparations [Perez et al 05] and the results confirmed that there is no significant difference on the microscopic roughness from a statistical standpoint. In fact, bond is more likely to be influenced by micro-roughness than macro-roughness [Courard 99, Garbacz et al 05]. But, in this analyse, rupture was considered to occur at the interface. However, as showed before, for rougher surface, the break sur- 
face doesn't follow the physical interface. As indicated in figure 3 , the breaks surface correspond to the interface surface only for flatter surface as SCA and $\mathrm{SAB}$ were. In the case of $\mathrm{WJ}$ and PJ7S, cracks propagation swing around the interface. In this condition, the results presented in figure 4 have no signification. Consequently, it's impossible to conclude about the relation between roughness and adhesion with this data.

\subsection{Relation between debonding and bond strength}

In regard to the debonding mechanism, the design of bonded concrete repair must take account of on the tensile stress perpendicular to the interface. This tensile debonding stress results of many effects like the flexural stiffness of the bending layer or the peeling effects [Granju 01]. Debonding initiates when the tensile stress at the interface exceeds the bond strength. So, it is impossible to observe a debonding until stress stays under the bond strength. This description highlights the prevalence of the tensile strength on the existence and the propagation of debonding. So the test which validates the quality of the execution of a repair is a test which makes it possible to characterize the tensile strength of the composite.

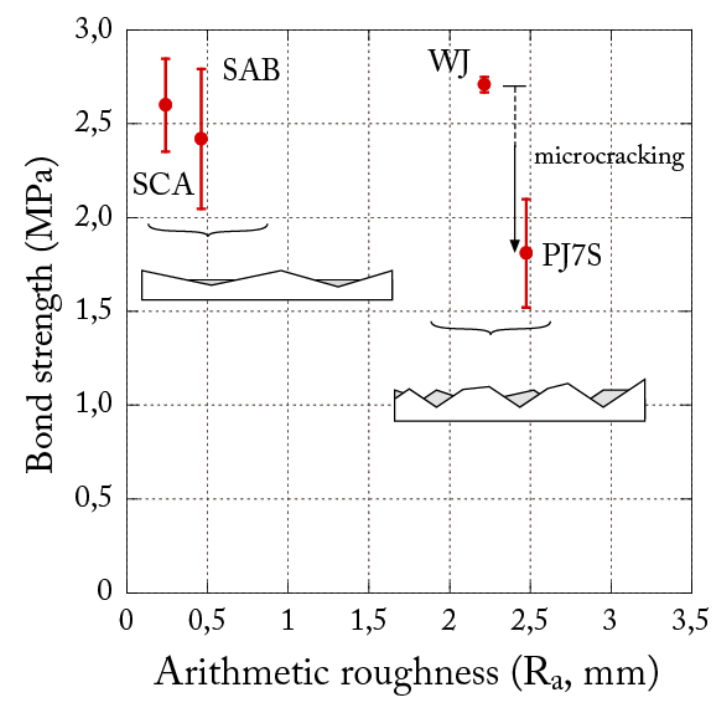

Figure 5 : Relation between adhesion and the roughness parameters $R_{a}$

Figure 6 presents the length of debonding measured during loading tests in function of the adhesion evaluation. The debonding obtained on SCA-beams indicate that an adherence of 2,60 MPa does not guarantee the monolithic behaviour whereas an adherence of 1,80 MPa (R-JP7S) seems to be sufficient. This debonding has modified the structural behaviour of these repaired SCA-beams. This result lets suppose that an inconsistency was appeared.
Adhesion appeared to be a non sufficient parameter to prevent debonding. Of course, a monolithic behaviour is impossible to achieve without a minimum of adhesion. But it's not enough. Whereas JP7S-beams have a much lower adhesion than SCA-beams, there was no debonding during structural tests.

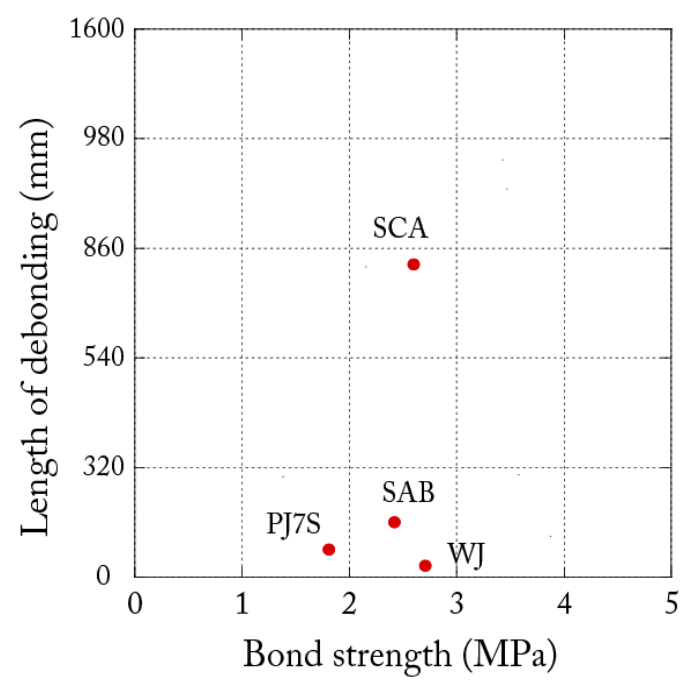

Figure 6 : Relation between adhesion and the debonding length

In the other side, SCA-beams configuration exhibited very high debonding with a much higher bonding strength. Finally, SCA-beams and SABbeams have the same bond strength and their structural behaviours were dissimilar. Theses differences can't be explained by the variation of the bond strength.

\subsection{Relation between debonding and roughness}

In fact, the relation between reduction of debonding risk and bonding strength came from a misunderstood. In literature [Silfwerbrand 90, Bernard 00], good bonding strength has been reported when a high roughness surface was produced by the surface preparation technique. In this case, no debonding was observed [Silfwerbrand 90, Bernard 00]. So, the appropriate structural behaviour has been often related to the good adhesion instead of roughness. Results below indicated that this assumption could not be sufficient.

Figure 7 present the length of debonding measured during loading tests in function of the roughness evaluation. It exists a roughness threshold above which the risk of debonding is reduced. In the configuration of this program, this threshold of $\alpha_{\text {rough, }}$ is equal to 8 degree, which correspond to the $\mathrm{SAB}$ preparation of surface. For the practical point of 
view, the roughness threshold should be estimated from the initial roughness, directly after the surface preparation.

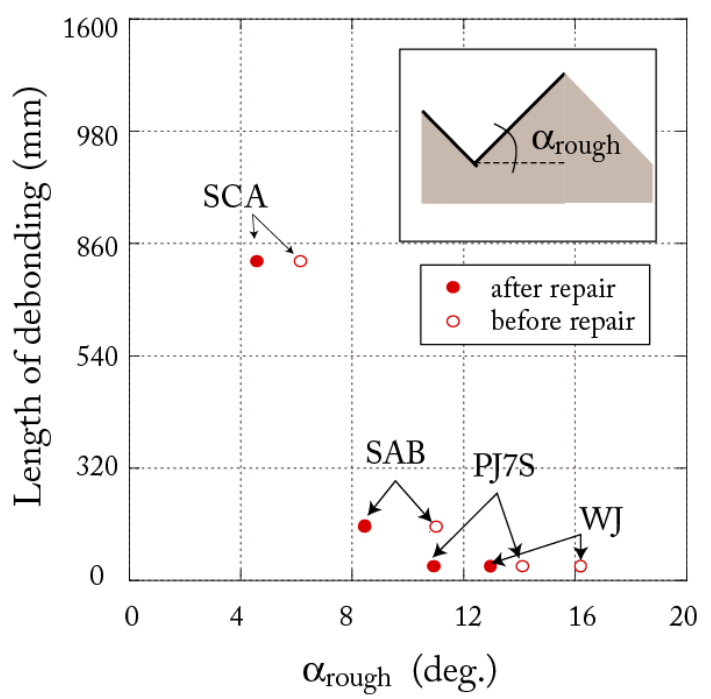

Figure 7 : Relation between debonding length and the roughness parameters $\alpha_{\text {rough }}$

As Figure 7 showed, there is a shift in the $\alpha_{\text {rough, }}$ between the estimation made before repair operation and after the tensile test. Explanations about this shift have been given previously on this subject. Regard to this, the threshold is about 11,8 degree for $\alpha_{\text {rough }}$ In addition, these values are not universal values. The stresses at the interface are a function of the flexural rigidity and of the thickness of the repair layer. For other beam geometry, the threshold could be different. But the concept will be the same. To obtain a monolithic structural behaviour, the surface roughness must exceed a certain threshold.

\subsection{PROPOSED APPROACH FOR DESIGN DURABLE REHABILITATION}

\subsubsection{Modification of the debonding mechanism}

As noticed previously, in regard to the debonding mechanism, the design of bonded concrete repair is made by taking account of the tensile stress perpendicular to the interface. Debonding initiates when the tensile stress at the interface exceeds the bond strength. But results obtained in this work indicated that debonding can occurs regardless the bond strength. Therefore, this parameter couldn't be use as a parameter to guaranty the repaired structure's durability. However, based on mechanical measurement, it was demonstrated that the interfacial surface is zone of less strength than bulk concrete. Then, it could be proposed that a local debonding always occurs in this weakness zone but its propagation is stopped rapidly. As noticed, the propagation is evaluated by the $\mathrm{G}_{\mathrm{F}}$ value. In [Perez 05], based on experimental measurements, a strong relation has been highlighted between the parameter $\alpha_{\text {rough }}$ and the energy $\mathrm{G}_{\mathrm{F}}$. This relation was in correspondence with other literature results [Büyüköztürk 98]. A propagation mechanism is proposed to take account of all theses new information.

\section{CONCLUSIONS}

The aim of the research was to better understand the mechanisms involved in the cracking behaviour of bonded overlays used on reinforced concrete beams. This works have focus on the influence of the surface preparation.

Through a variety of measurements on substrate surfaces and on concrete to concrete break surfaces with the non-contact method, the roughness of surface and of the fracture surface have been investigated. A complete evaluation of the bond developed between repair material and substrate has been made. Experimental study, as presented in this paper, emphasizes the influence of surface roughness on the structural behavior of repaired beams and on the debonding mechanism. Although tensile bond has been proposed by many investigators as a tool to evaluate the structural behavior of repaired beams, it is, regard to results obtained, that this parameter alone is not sufficient enough to assess the monolithic behavior, especially for cases of relative flat surface preparation. Results indicate that increase the roughness does not enhance the bond strength. The result of the characterization and image analysis of fracture pattern, roughness parameters and binary image stacks are essential geometric and morphological information required in a mechanical model of fracture. The modification of the debonding model proposed to use the angle $\alpha_{\text {rough }}$ as parameter to control the interface debonding. The local angle $\alpha_{\text {rough }}$ along the crack progression is determined from the topography analysis. Then, to insure monolithic behaviour, surface treatment must produce a minimal adhesion and must induce a certain level of roughness. While the roughness is higher than a certain threshold, the debonding risk decrease rapidly and monolithic behaviour is reached. By taking the roughness angle $\alpha_{\text {rough }}$ as design parameter for repaired structure, it makes possible to evaluate the potential durability of structure even before the casting of the repair material. In opposite, the evaluation of the bond strength can only be done when the concrete has reached a certain level of maturity. Then, if the repaired proves to be inadequate, the only exit resides in to the destruction 
of the superficial layer of repair material. This step generates expansive socials and economics costs.

\section{REFERENCES}

Abu-Tair A.I., Lavery D., Nadjai A., Rigden S.R., Ahmed T.M.A. (2000), A new method for evaluating the surface roughness of concrete cut for repair or strengthening, Construction and Building Materials, 14, pp 171-176

Bernard O., (2000), Comportement à long terme d'éléments de structures formées de bétons d'âges différents. $\mathrm{PhD}$ thesis, EPFL.

Belair N. Jr , (2006), Contribution à la mise au point d'une procédure de caractérisation quantitative des surfaces en béton en vue de travaux de réfection M.Sc. Thesis, Sciences and Engineering Faculty, Université Laval, Québec, Canada, CRIB.

Bijen J. and Salet T., (1994), Adherence of young concrete to old concrete development of tools for engineering. In Proceeding of 2nd Bolomey Worshop on Adherence of Young on Old Concrete., pages 1-24. Wittman, F.W..

Büyüköztürk O. and Hearing B. (1998) crack propagation in concrete composites influenced by interface fracture parameters, In. J Solids Structures Vol. 35, N 31, pp. 4055-4066

Chausson H., (1998), Pratique des réhabilitations en mortier projeté renforcé de fibraflex - 10 ans d'acquis. In 3ième Colloque International Francophone sur Les Bétons Renforcés de Fibres Métalliques, St Foy, Québec.

Chiai B., Van Mier J.G.M. and Vervuurt A., (1998), Crack growth mechanisms in four different concretes: microscopic observations and fractal analysis, Cement and concrete research, v28,n1,pp103.114

Concrete Society (The U.K.) (1991). 'Patch repair of reinforced concrete. Model specification and method of measurement'. Concrete Society Technical Report No. 38.

Courard L., (1999), Contribution à l'analyse des paramètres influençant la création de l'interface entre un béton et un système de réparation. Appétence et adhérence: cause et effet d'une liaison". PhD thesis, Université de Liège, Collection des Publications de la Faculté des Sciences Appliquées, No. 192, 213 pp.

Courard, L., (2000). Parametric Study for the Creation of the Interface between Concrete and Repairs Products. Mater. Struct., 33 (225) 65-72.

Courard, L, Bissonnette B. and Belair N. ${ }^{\mathrm{Jr}}$, (2005). Effect of surface preparation techniques on the cohesion of superficial concrete: Comparison of jack-hammering and water jetting, In: ICCRRR 2005 International Conference on Concrete Repair, Rehabilitation and Retrofitting (Eds. H. Beushausen, F. Dehn and M.G. Alexander), Cape Town, South Africa (Nov.21-23).

Cusson D. and Mailvaganam N., (1996), Durability of repair materials. Concrete international, pages 34-38, march.
Denarié. E.(2000), Etude expérimentale des couplages viscoelastique - Croissance des fissures dans les bétons de ciment. PhD thesis, EPFL.

Friebrich M.H., (1993) Influence of the surface rougghness on the adhesion between concrete and gunite mortars overlays. Proceeding of 2nd Bolomey worshop on adherence of young on old concrete., pages 107-114

Garbacz A, Górka M and Courard L., (2005), On the effect of concrete surface treatment on adhesion in repair systems. Mag Concr Res, 57:49-60.

Granju J.L., (1996), Fibre reinforced thin concrete overlays : The mechanism of their debonding in relation with their cracking. Concrete Repair, Rehabilitation and Protection, pages $583-590$.

Granju J.L., (2001), Debonding of thin cement-based overlays. journal of materials in civil engineering, pages 114-120, March-April.

Granju J.L., Sabathier V., Turatsinze A, Toumi T, (2004), Interface between an old concrete and a bonded overlay: debonding mechanism, Interface Science, vol. 12, pp 381-388.

Wheat D.I., Fowler D.W. and Al-Negheimish A.I., (1993), Thermal and fatigue behavior of polymer concrete overlaid beams. journal of materials in civil engineering, pages 110118 .

Hilsdorf H.K., Gunter M. and Haardt P., (1992), Fracture mechanics application in the analysis of concrete repair and protection systems. Fracture Mechanics of concrete Structures, pages 951-959.

Laurence O., (2001), La fissuration due au retrait restreint dans les réparations minces en béton : apport combiné de l'expérience et de la modélisation. PhD thesis, Université Laval, CRIB, Canada.

Lupien C., Chanvillard G., Aïtcin P.-C., and Gagné. (1995). Réhabilitation d'une chaussée par resurfaçage mince adhérent en béton renforcé de fibres d'acier. pages 246-250. ASCE.

Maerz H., Nanni A., J.Myers J. and Galecki Greg (2001). Laser profilometry for concrete substrate characterization prior to FRP laminate application. Concrete Repair bulletin. May-June, pp 4-8.

Mellinger F.M., (1963), Structural design of concrete overlays. ACI journal, 60(2) :225-237, 1963.

Momayez A., Ehmasi M.R., Ramezanianpour A.A. and Rajaie H. (2005), Comparison of methods for evaluating bond strength between concrete substrate and repair materials, Cement and Concrete Research, 35, 748-757.

Ong K.C.C., Paramasivam P., Ong B.G. and Lee S.L., (1995),. Probabilistic approach to fatigue life prediction of repaired reinforced concrete slabs. ACI Structural journal, 92(5).

Perez F., Bissonnette B. and Courard L., (2003), Outils de caractérisation paramétrique de la rugosité des surfaces en béton: nouveaux développements. Journées scientifiques $\mathrm{du} \mathrm{RF}^{2} \mathrm{~B}$, 25-26 August, Sherbrooke, Canada, 10p. 
Perez F., Courard L., Bissonnette B., Garbacz A. and Gorka M., (2005), Comparison of two different techniques for the evaluation of concrete surface roughness. In: ICCRRR 2005 International Conference on Concrete Repair, Rehabilitation and Retrofitting (Eds. H. Beushausen, F. Dehn and M.G. Alexander), Cape Town, South Africa (Nov.21-23).

Perez F., (2005), Contribution à l'étude du comportement mécanique des éléments bi-couches composés de bétons d'âges différents sous sollicitations statiques et dynamiques. Ph.D. Thesis, Sciences and Engineering Faculty, Université Laval, Québec, Canada, CRIB.

Perez F., Bissonnette B. and Gagné R., (2007), Parameters affecting the cracking behavior of bonded overlays used on reinforced concrete slab subjected to flexural loading,

Saiidi M., Vrontinos S, and Douglas B., (1990), Model for the response of reinforced concrete beams strengthened by concrete overlays, ACI structural Journal, v87, n6, pp687-695.

Rossi, P., Ulm, F.-J., Hachi, F., (1996), "Compressive behaviour of concrete: physical mechanisms and modeling", Journal of Engineering Mechanics, ASCE, vol. 122, $\mathrm{n}^{\circ} 11$, pp. $1038-1043$

Santos P.M.D., Jùlio E.N.B.S., Silva V.D., (2007), Correlation between concrete-to-concrete bond strength and the roughness of the substrate surface, Construction and Building Materials $211688-1695$

Saucier.F., (1990) La Durabilité de L'adhérence Des Réparations En Béton. Ph.D. Thesis, Sciences and Engineering Faculty, Université Laval, Québec, Canada, CRIB.

Scapinato E.J., (1996), Thin polymer concrete bridge deck overlays. Concrete construction.

Silfwerbrand J., (1990), Improving concrete bond in repaired bridge decks. Concrete International, September: 61-66.

Talbot C., Pigeon M., Beaupré D., and Morgan D.R., (1994), Influence of surface preparation on long-term bonding of shotcrete. ACI Materials Journal, November-December :560566. 